\title{
Quake or Blast? - Classifying Events in the Carajás Mining Region
}

Julia Prado', Bruno Collaço1, Raphael Prieto², Marcelo Bianchi'1, 1Seismology Center (USP), 2Vale S.A.

Copyright 2021, SBGf - Sociedade Brasileira de Geofísica.

This paper was prepared for presentation during the 17th International Congress of the Brazilian Geophysical Society held in Rio de Janeiro, Brazil, 16-19 August 2021.

Contents of this paper were reviewed by the Technical Committee of the $17^{\text {th }}$ International Congress of the Brazilian Geophysical Society and do not necessarily represent any position of the SBGf, its officers or members. Electronic reproduction or storage of any part of this paper for commercial purposes without the written consent of the Brazilian Geophysical Society is
prohibited.

\section{Abstract}

In the Carajás region (Para, Brazil), seismic events such as quarry-blasts, induced earthquakes and regional earthquakes are routinely identified. Blasts are tools of the daily work of the mines, induced earthquakes are those that occur naturally due to the interventions in the mining area and natural earthquakes are the result of regional tectonic sources of natural occurrence, unrelated to the interventions of exploration.

Although there is a difference in the waveform signature between blasts and earthquakes, the classification of these events many times are still based on the operating hours of the mines and the distances between mines and epicenters.

This work presents a method to evaluate in quantitative ways how to separate events into two sets, induced earthquakes and quarry-blasts. The proposal aims to offer an efficient tool to classify events detected in the Carajás region.

Beside the seismograms, this tool also uses appropriate parameters such as the amplitude ratio between $S$ and P-waves, the shape of the power spectrum of the events, magnitude values, duration, frequency and spectrograms. Each parameter was used to build a decision matrix, that will take into account every result to make the final classification.

The first results were then compared to events reported as quarry-blasts by local mines personnel with given time and location. For the induced earthquakes classifying tests, we used events which occurred at dawn near the mines, and also reported by the personnel that felt the event.

The Quake or Blast? method proves to give reliable solutions. Nevertheless, this cannot be generalized mostly because many parameters in the decision matrix are "station dependent", so values may vary with the region. 